\title{
Helix, o streaming de memórias de Assassin's Creed Unity ${ }^{1}$
}

Karen K. Kremer ${ }^{2}$

Resumo: Ao entender a memória como um constructo social, é imprescindível pensar seu papel e lugar na sociedade tecnológica contemporânea. À primeira vista, pode parecer anacrônica a existência de uma conexão entre história e tecnologia: mero engano. A história pode ser usada como instrumento de poder e dominação, ao criar um imaginário coletivo coerente com os valores e ideais da classe dominante, ou, ainda, ser usada para roubar a memória de indivíduos e usá-la contra eles. Este é o cerne do Helix, serviço de streaming de memórias integrante do game Assassin's Creed Unity (Ubisoft, 2014), que explora os meandros da resistência à cultura dominante e exibe a potencialidade da história em se tornar uma forma de estratégia a favor de determinadas ideologias, correspondendo à teoria certeauniana de poder.

Palavras-chave: Games; História; Memória; Assassin’s Creed;

Abstract: By understanding memory as a social construct, it is essential to think their role and place in contemporary technological society. At first glance, it may seem anachronistic the existence of a connection between history and technology, mere mistake. The history can be used as an instrument of power and domination to create a coherent collective imagination with the values and ideals of the ruling class, or even be used to steal the memory of individuals and use it against them. This is the Helix core, streaming service of memories integral the game Assassin's Creed Unity

${ }^{1}$ Artigo elaborado a partir do desenvolvimento dos estudos da disciplina Tópicos em História e Ciências Sociais, ministrada pela Profa. Dra. Andrea Mazurok Schactae em 2014, no curso de Bacharelado em História da Universidade Estadual de Ponta Grossa (UEPG).

${ }^{2}$ Bacharel em História e mestranda do Programa de Pós-Graduação em História, Cultura e Identidades da Universidade Estadual de Ponta Grossa (UEPG). Cineasta, membro da International Screenwriters' Association (ISA). Redatora do GameBlast. E-mail: bat.karen@hotmail.com 
(Ubisoft, 2014), which explores the intricacies of resistance to the dominant culture, and shows the potential of history to become a form of strategy of certain ideologies, corresponding to Certeau's theory of power.

Keywords: Games; History; Memory; Assassin's Creed;

\section{Memória: a janela para o passado e para o futuro}

Partindo da premissa de Jacques Le Goff (1996) ${ }^{3}$ da existência de duas histórias: da memória coletiva e dos historiadores, relacionaremos estas formas de história na busca por compreender esta relação de saber e poder capaz de mudar a sociedade, raciocínio utilizado no game histórico ficcional Assassin's Creed Unity (Ubisoft, 2014).

Segundo Pollak (1989), a memória coletiva refere-se aos pontos de referência da memória que a estruturam dentro de uma coletividade. Como monumentos, lugares, construções arquitetônicas e outros. Referências presentes na memória de vários indivíduos; por exemplo, a Torre Eiffel constitui-se numa memória coletiva das pessoas, em especial do povo francês, pois trata-se de uma memória compartilhada e lembrada por um coletivo, fazendo parte de suas identidades como franceses.

Le Goff (1996) classifica a memória coletiva como mítica e anacrônica, reflexo de uma conexão incompleta entre passado e presente; em contrapartida, entende a história produzida pelo historiador

${ }^{3}$ Historiador francês especialista em Idade Média. 
como aquela que deve mostrar a verdade e revelar os enganos oriundos da memória coletiva. Porém, o historiador francês usa desta organização teórica inicial para questionar justamente a "imparcialidade inerente" que é atribuída ao historiador. Neste quesito reside o poder da história.

A vida da criança mergulha mais do que se imagina nos meios sociais através dos quais entre em contato com um passado mais ou menos distante, e que é como que o quadro dentro do qual são guardadas as suas lembranças mais pessoais. É esse passado vivido, bem mais do que o passado apreendido pela história escrita, sobre o qual poderá mais tarde apoiar-se sua memória. (HALBWACHS, 1990, p. 71).

Não apenas a criança, mas o jovem, o adulto e o idoso também estão imersos em um meio social, cujas experiências de vida lhes serão suas memórias mais marcantes. De acordo com Maurice Halbwachs $(1990)^{4}$, o passado vivido é o elemento mais presente na memória de uma coletividade.

A história escrita, apesar de seu poder de discurso e representatividade, não consegue fixar-se na memória de um indivíduo como, por exemplo, experiências vividas pessoalmente ou uma história de apelo audiovisual.

\footnotetext{
${ }^{4}$ Sociólogo francês da Escola Durkheimiana, célebre por seu estudo do conceito de memória coletiva.
} 
Dito isso, é justamente nesta vivência pessoal de integrantes de uma coletividade que se foca o Helix, serviço fictício de streaming ${ }^{5}$ de memórias em Assassin's Creed Unity. No game, o jogador é imerso neste serviço digital de entretenimento proporcionado pelas memórias dos ancestrais de pessoas secretamente usadas em experiências genéticas da Abstergo Industries.

No Helix é possível vivenciar diversos momentos da história, em uma espécie de videolocadora digital, cabendo ao usuário escolher qual episódio da história irá conhecer.

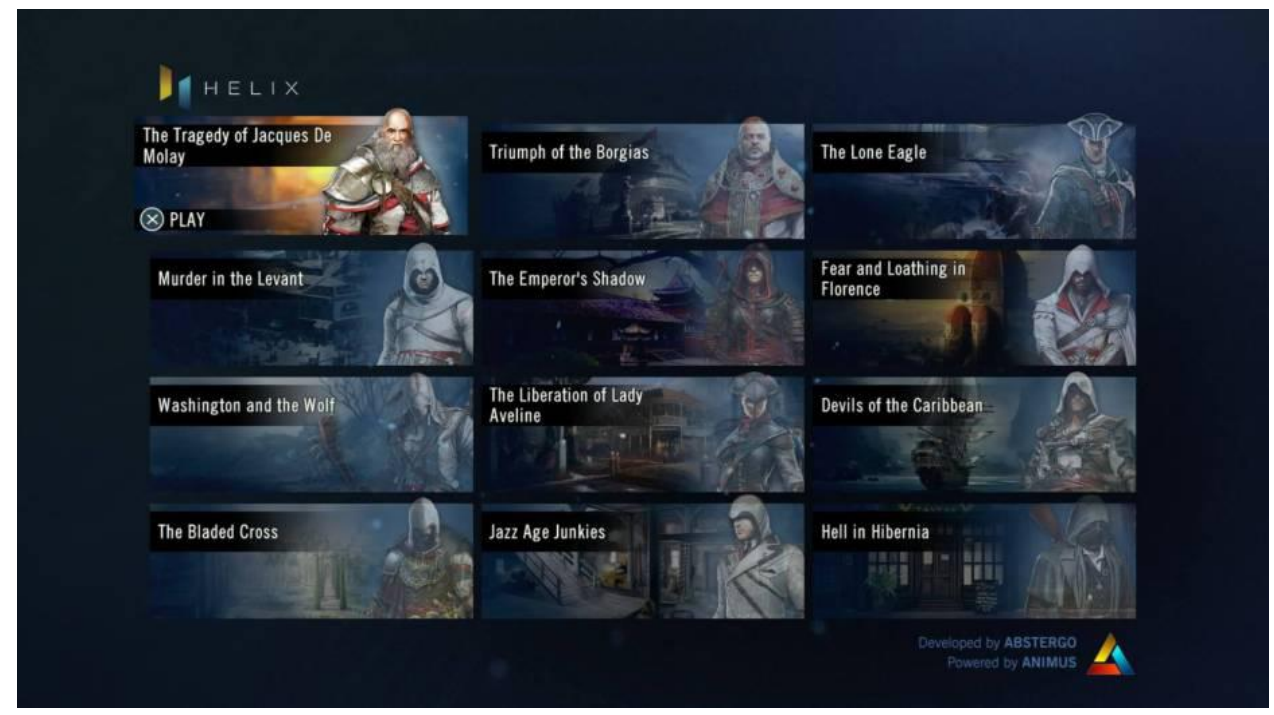

Figura 1 - Menu do Helix. Episódios históricos em forma de catálogo online de filmes ou séries de TV. Fonte: Assassin's Creed Unity.

${ }^{5}$ Distribuição de conteúdo através da internet. 
A Tragédia de Jacques de Molay, Triunfo dos Borgias, A Águia Solitária, Assassinato no Levante, A Sombra do Imperador, Medo e Repugnância em Florença, Washington e o Lobo, A Libertação da Dama Aveline, Demônios do Caribe, A Encruzilhada de Lâminas, Drogados da Era do Jazz e Inferno em Hibérnia ${ }^{6}$ são as memórias disponíveis para o usuário.

É neste cenário que o poder e a dominação por meio da história são construídos. No game, o Helix é uma plataforma de entretenimento criada pela Abstergo Entertainment, subdivisão da Abstergo Industries, controlada pelos templários da atualidade, vilões das histórias da série Assassin's Creed. Assim, o serviço de streaming serve como disseminador da ideologia templária, contrária aos valores da Ordem dos Assassinos - os heróis do game.

Então, onde está a questão de memória, poder e mídia? Em toda a concepção do Helix, que serve como exemplo da utilização da história como fonte de controle da memória da coletividade.

Porém, há a pergunta central que este trabalho se propõe a responder: como a história - às vezes distante e distinta da realidade de um indivíduo - pode ser vinculada a ele?

${ }^{6}$ Títulos da versão brasileira do game. 
Utilizando como fonte o game Assassin's Creed Unity e como base os escritos de Denys Cuche ${ }^{7}$, Pierre Bourdieu ${ }^{8}$ e Michel de Certeau ${ }^{9}$, exploraremos o poder da memória coletiva, construída estrategicamente através dos meios midiáticos para convencer as pessoas da ideologia de um grupo dominante da sociedade.

\section{A cultura da memória: dominação subliminar}

A memória é parte da identidade de um povo ou nação, portanto, mudar a memória é mudar as pessoas. Porém, como chegar até esse ponto profundo do indivíduo? Como manipulá-la? Através da cultura. Para alcançarmos a memória de uma pessoa é preciso inserir-se no seu meio social, sua cultura.

Muitos pesquisadores constroem os conceitos centrais de seus textos utilizando o termo cultura como base de sua pesquisa; no entanto, a que se referem estes teóricos quando escrevem cultura? Um conjunto de intelectuais com gosto para arte e música clássica? Pessoas que frequentam museus, teatros e galerias de arte? Ou indivíduos comuns que adquirem seus saberes no seu dia-a-dia?

No presente texto, utilizarei o conceito de cultura do antropólogo Denys Cuche (1999), que entende a mesma como uma construção histórica gerada pela relação entre grupos sociais, para

\footnotetext{
${ }^{7}$ Sociólogo francês. Doutor em Etnologia pela antiga Sorbonne.

${ }^{8}$ Sociólogo francês. Foi docente na École de Sociologie du Collège de France.

${ }^{9}$ Historiador francês. Doutor em Teologia pela antiga Sorbonne.
} 
discorrer sobre algumas observações sobre o conceito de cultura para os teóricos Pierre Bourdieu (1996) e Michel de Certeau (1998), bem como o entrelaçamento entre cultura e história na construção da memória coletiva.

Seguindo a ideia de Cuche (1999), a cultura é uma construção social oriunda das relações do indivíduo com outros indivíduos dentro de uma sociedade com regras e hierarquias. Assim sendo, se a cultura é uma construção, significa dizer que há diferenças culturais, logo, mesmo em uma cultura coletiva, em seu interior há especificidades de cada grupo. Todavia, para a elaboração de uma memória coletiva é necessário um ponto-chave a que todos se sintam atrelados.

Para Bourdieu (1996), as noções de espaço social e espaço simbólico são realidades empíricas que provêm desta identidade de cada grupo social. O espaço só existe a partir da relação - atuação humana e a distinção entre grupos sociais só existe em relação ao outro.

Quando descrevo o espaço social global como um campo, isto é, ao mesmo tempo, como um campo de forças, cuja necessidade se impõe aos agentes que nele se encontram envolvidos, e como um campo de lutas, no interior do qual os agentes se enfrentam, com meios e fins diferenciados conforme sua posição na estrutura do campo de forças, contribuindo assim para a conservação ou a transformação de sua estrutura. (BOURDIEU, 1996, p. 50). 
A afirmação de Bourdieu (1996) remete à ideia de resistência e luta de forças convergentes. Há conflitos entre os grupos sociais de um mesmo espaço. A exemplo, citemos a intervenção da personagem Bispo - membro da Ordem dos Assassinos - durante a primeira missão de Assassin's Creed Unity: A Tragédia de Jacques de Molay.

Após findar a fase em questão, uma interferência proposital é feita aos servidores do Helix no intuito de contatar um usuário do sistema de streaming - no caso, o jogador do game - para alertá-lo quanto aos reais propósitos do Helix e da Abstergo. Na mensagem, Bispo avisa ao usuário que a Abstergo está usando o Helix para acessar seus neurônios e vasculhar suas memórias genéticas com o objetivo de controlar a história da humanidade.

O que remete ao pensamento de Cuche (1999), onde ele faz a distinção entre cultura dominante e cultura dominada, cultura popular e cultura burguesa. A Abstergo Industries, através do controle de corporações, governos, ONGs e mídias, dissemina uma cultura que provém da ideologia templária, todavia, mostrando-a como parte da história de toda sociedade no papel de cultura dominante dentro do universo do game.

Ao analisarmos os títulos e descrições das fases presentes no menu da plataforma Helix, percebe-se o discurso heroico proferido aos templários em detrimento da criminalização dos assassinos. Ou seja, cria-se uma história de exaltação da figura do templário e se descontrói 
ou retira a identidade, cultura e valores da Ordem dos Assassinos, atribuindo-lhes um lugar sombrio na história, com o objetivo de transformar esta representação em uma memória coletiva contra os Assassinos.

Tomaremos por exemplo a primeira missão jogável: A Tragédia de Jacques de Molay. Nela, o jogador é transportado para a Paris de 1307, na pele de um cavaleiro templário que acompanha as últimas horas de Jacques de Molay, antes de ver o grão-mestre da Ordem dos Cavaleiros Templários ser capturado pelo exército do Rei Filipe IV e, posteriormente, ser morto por um Assassino. 


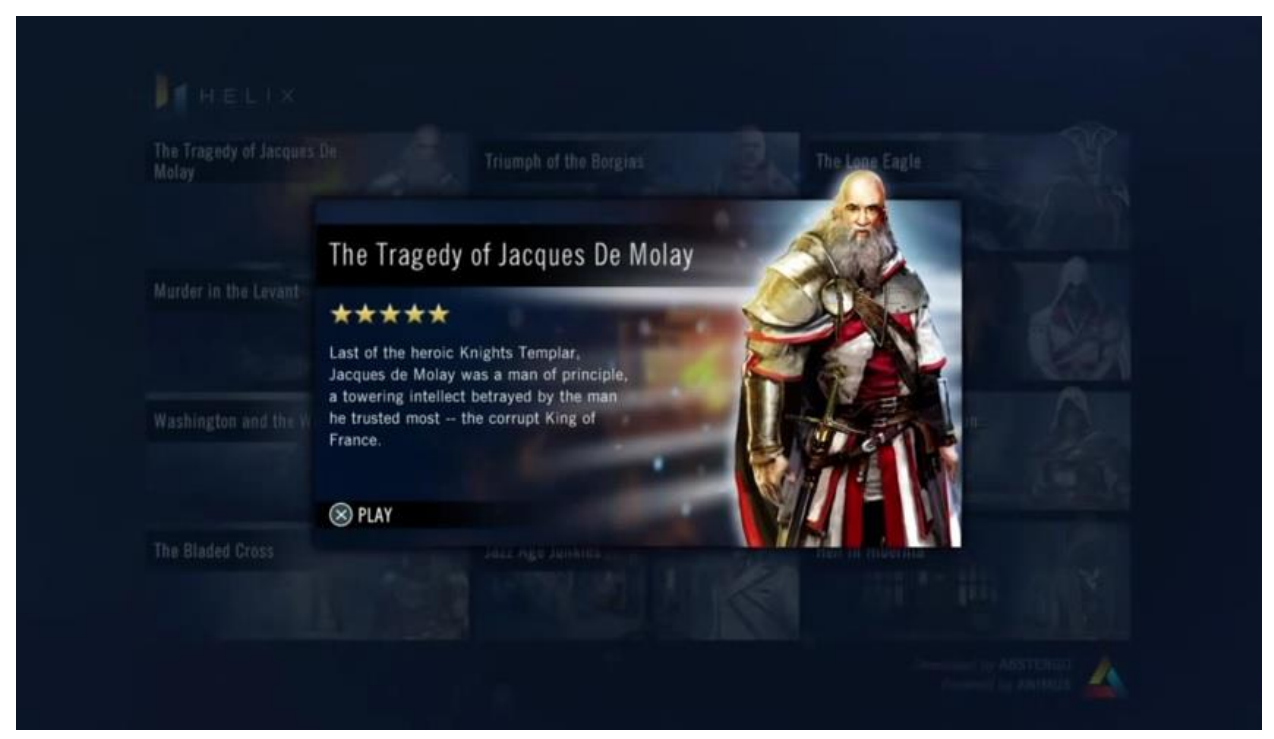

Figura 2 - A Tragédia de Jacques de Molay. O grão-mestre da Ordem dos Cavaleiros Templários é vitimizado e apresentado na posição de mártir pela Abstergo Entertainment. Fonte: Assassin's Creed Unity.

No entanto, ao tomarmos a concepção de cultura de Cuche (1999) - cultura dominante e cultura dominada, cultura popular e cultura burguesa -, devemos ter em mente que este tipo de classificação só é possível utilizando o método de comparação, afinal, se a cultura fosse homogênea, não haveria divisões e classificações como "melhor" ou "pior". Deste modo, quando dizemos que uma determinada cultura é popular e outra cultura é de elite estamos criando, mesmo inconscientemente, uma diferença entre ambas, o que pode culminar 
num processo de juízo de valor como "esta cultura é superior a aquela" ou "aquela cultura é inferior a esta".

Isso não quer dizer que necessariamente toda subdivisão referese a um julgamento de valor, mas que este tipo de pensamento é o predominante em nossa sociedade: o maniqueísmo. O bom e o mau, o melhor e o pior, o superior e o inferior. As pessoas procuram diariamente um meio de se sobressair aos demais, e o ato de diferenciar sua cultura das demais é um dos meios pelos quais diversos grupos sentem-se superiores a outros. Este é o papel do Helix, mostrar a cultura dos templários como superior e a dos Assassinos como inferior. Uma construção conscientemente ideológica de história, usando a memória como ferramenta de poder.

Para Certeau (1998), o conceito central de cultura foca-se na apropriação. O consumo cotidiano de informação e a percepção de sociedade. Como os sujeitos se apropriam do que lhes é imposto pelo sistema, um sistema repleto de meios midiáticos que injeta diariamente um discurso a favor do grupo dominante.

Fomos ensinados a pensar que quando se trata do consumo de informação gerado pelos meios de comunicação, a população aceita passivamente o sistema imposto. No entanto, é justamente neste aspecto que Certeau (1998) busca mostrar sua tese: as práticas cotidianas subvertem o discurso oficial. 
Os indivíduos são complexos e nenhuma "teoria universal" pode compreendê-los totalmente. Ao contrário do pensamento naturalizado pelo meio acadêmico, as pessoas não são simples robôs que ingerem toda informação recebida e agem do modo esperado pelo seu criador. A massa possui a capacidade de subverter, ela não é completamente manipulada, como a maioria dos pesquisadores julgam, mas as pessoas usam o que lhes é imposto a seu favor. Elas consomem à sua maneira.

Em Assassin's Creed Unity você assume o controle de um usuário comum do sistema Helix que é convocado por Bispo e pela Ordem dos Assassinos a resistir e lutar contra os templários e seu discurso dominante. Contudo, seria isto um paradoxo? Afinal, se estamos usando o Helix, como lutaremos contra ele? Parece um labirinto sem saída, mas não é.

De acordo com Certeau (1998), a prática cotidiana subverte a imposição oficial, assim, trata-se da forma de ler e consumir o que lhe é imposto. Então, é possível lutar contra o sistema, dentro do sistema, ou mesmo se utilizando dele. Tal prática não faz dos indivíduos hipócritas quanto a seus valores e ideais, mas compreende esta subversão do oficial como forma de resistência. 


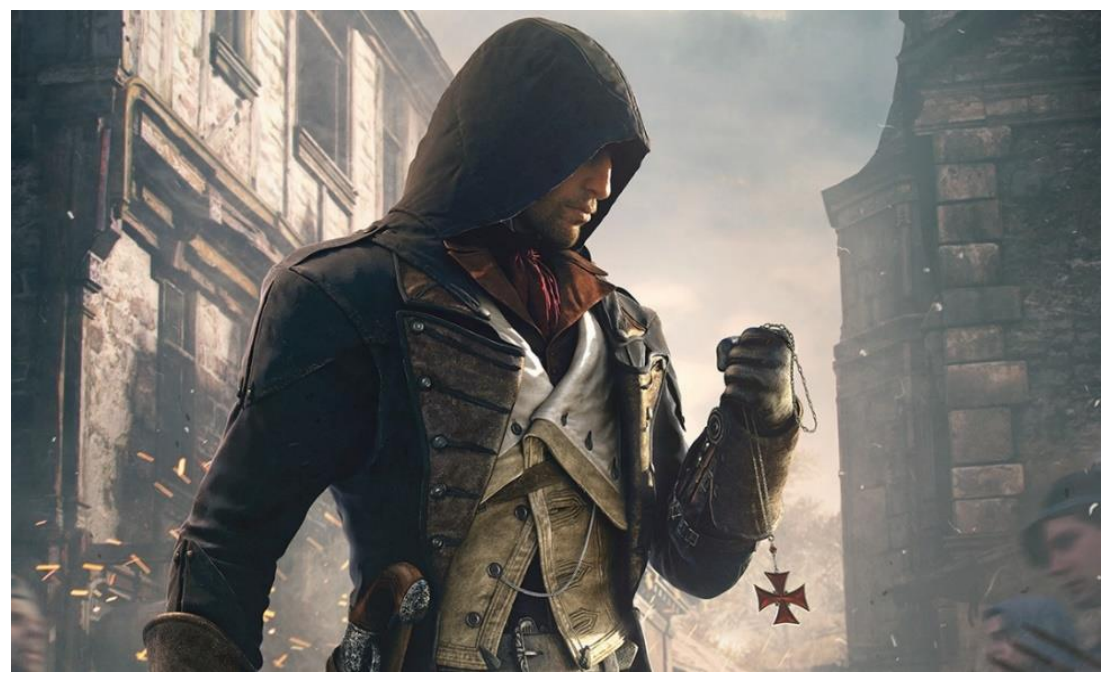

Figura 3 - Após a intervenção de Bispo, o jogador assume o controle do assassino Arno Dorian durante a Revolução Francesa. Fonte: Divulgação Ubisoft.

Para lutar contra a Abstergo, a Ordem dos Assassinos se utilizou do próprio banco de memórias da empresa para revelar os segredos do discurso templário oficial. Assim, não se trata de submissão, mas de resistência da massa contra a cultura dominante. Mas talvez esse tipo de pensamento hierárquico e determinista faça bem ao ego dos teóricos que integram a comunidade acadêmica, que por terem uma posição privilegiada socialmente pensam que estão isentos da influência do sistema. Deste modo, é fácil reduzir a população a simples massa de manobra e a si mesmos como pessoas altamente capacitadas e que não se deixam levar pelo discurso oficial da sociedade. 
Cria-se um tipo de "cultura superior acadêmica", o que nada mais é do que uma simples utopia. Este é um tabu que Certeau (1988) quebra ao estudar a recepção de informação e mostrar a resistência da população frente às regras que a sociedade lhe impõe. Não como meros seres passivos, desprovidos de cultura própria, que seguem cegamente a cultura dominante, cuja ideologia é rechaçada pela "elite intelectual acadêmica".

Assim sendo, para Certeau (1998), a população subjugada pelo que Denis Cuche (1999) chama de cultura dominante não aceita passivamente o sistema que lhe é imposto. Uma coisa é o que a TV e a internet projetam, outra é como as pessoas reagem. A pessoa escolhe como ela vai consumir. Isto é o que Certeau (1998) chama de estratégia e tática.

A estratégia é a decisão já tomada e a tática são as decisões a serem tomadas no momento. Por exemplo, em uma guerra a estratégia é entregue pronta aos soldados, mas no campo de batalha são eles que tomam as próprias decisões. Assim é a sociedade. A grande massa é excluída do processo da produção de bens que lhe são impostos diariamente, ela consome o que lhe é oferecido, porém, ela tem a opção de reinventar o produto, burlar o sistema e não concordar com o seu discurso. 


\section{O passado como playground?}

O Helix é um serviço de streaming fictício do universo de Assassin's Creed Unity ou não? Se aplicarmos o conceito de idealização da plataforma de entretenimento da Abstergo ao mundo real - não o virtual -, será que não vivemos a mesma experiência proporcionada pelo game?

O cinema, a televisão, a música e a arte também não são experiências imersivas com um discurso próprio de seus criadores? Não é a indústria midiática que dita quais são os padrões culturais a serem seguidos?

Qual corte de cabelo é o ideal? Qual é a roupa da moda? Qual aparência possuir? Que peso ter? Quais lugares frequentar? Que carros comprar? Que bebidas beber? Que comidas comer? Para onde viajar? Com que pessoas sair? Com quem se casar? Que religião seguir? Quais músicas ouvir? Como se comportar? Qual vocabulário utilizar? Qual profissão é melhor? Quais livros ler?

A mídia, controlada por um grupo de indivíduos, injeta todos os dias no corpo da sociedade doses da ideologia que serve aos interesses dos dominadores. Certeau afirma: "O desenvolvimento excepcional, até mesmo canceroso, dos procedimentos panópticos parece indissociável do papel histórico que lhes foi atribuído, o de ser uma arma para combater práticas heterogêneas e para controlá-las" (CERTEAU, 1998, p. 115). Ou seja, os atuais meios midiáticos de que a sociedade dispõe 
não são nada mais do que novos instrumentos tecnológicos de vigilância e monitoramento da população. Ferramentas de controle e poder. A história é uma arma oriunda da população, mas que tem sua mira virada para ela.

A cultura dominante se utiliza dos próprios recursos da cultura dominada contra ela. Como no Helix, em que o indivíduo tem sua memória vasculhada, monitorada e roubada, o sistema dominante faz o mesmo. Através da mídia cria-se a história dos vencedores e a história dos vencidos. A memória é manipulada visando interesses econômicos, políticos e individuais. O Helix abre nossa mente para enxergar além do óbvio, não se trata do elemento de um game, se trata da própria história e do lugar e papel que a contemporaneidade tem lhe atribuído. A história sempre foi utilizada como instrumento de dominação, entretanto, em um século mecanicista e tecnológico como o atual, a adulteração proposital da história com propósitos escusos e egoístas tem se alastrado como uma praga sobre a nova geração. A facilidade de produção e distribuição de informação ajuda grupos ideológicos dominantes a propagar seus valores e ideais através de um discurso persuasivo que faça a população acreditar que ela necessita do que a elite precisa. Cria-se a ilusão de memória coletiva, onde a coletividade é refém de um discurso que não se adequa a seus valores e necessidades.

Quais são os momentos mais importantes da história? Que datas estão nos calendários? Quais homenagens fazer? Quais movimentos 
sociais apoiar? Quais pessoas são ameaças à sociedade? De quem são as estátuas nas ruas das cidades? Quais inventos são mais valiosos? Qual país é o melhor? Qual religião é mais importante? O que é mentira e o que é verdade? Qual cultura é superior? Enfim, de quem é a memória vigente?

A cultura é muito mais complexa que uma simples afirmação generalizadora, ela envolve ao mesmo tempo o aspecto coletivo e individual, pois, apesar de estarmos inseridos em uma cultura global, também possuímos especificidades de uma cultura particular desenvolvida a partir das nossas relações sociais.

Então, mesmo vivendo sob o domínio de uma cultura memorialista ideológica é possível resistir, reinventar e lutar. O Helix é real, ele é as formas de entretenimento em massa da contemporaneidade e nós somos a Ordem dos Assassinos, o remanescente de uma contracultura à pós-modernidade. Como diz a música-tema de Assassin's Creed Unity, "todos querem governar o mundo" (LORDE, 2014).

\section{Referências:}

ASSASSIN'S CREED UNITY. Ubisoft, XBox One, 2014.

BOURDIEU, Pierre. Razões Práticas. São Paulo: Papirus, 1996.

CERTEAU, Michel de. A Invenção do Cotidiano. Rio de Janeiro: Vozes, 1998. 
CUCHE, Denys. A Noção de Cultura nas Ciências Sociais. Bauru: EDUSC, 1999.

HALBWACHS, Maurice. A Memória Coletiva. São Paulo: Vértice, 1990.

LE GOFF, Jacques. História e Memória. 4. ed. Campinas: Unicamp, 1996.

LORDE. Everybody Wants to Rule the World. Composição original: Tears for Fears, 1985. Trilha sonora de ASSASSIN'S CREED UNITY. Ubisoft, XBox One, 2014.

POLLAK, Michael. Memória, Esquecimento, Silêncio. Estudos Históricos, Rio de Janeiro v. 1, n. 1, p. 3-15, 1989.

UBISOFT. Assassin's Creed Unity E3 2014 World Premiere Cinematic Trailer [EUROPE]. Disponível em: $<$ https://www.youtube.com/watch? $\mathrm{v}=\mathrm{xzCEdSKMkdU>}$. Acesso em: 09 set. 2015.

Recebido em 31/10/2015, aceito para publicação em 27/09/2016 